\title{
HbA1C: Universal Screening versus NICE Guidelines in Acute Coronary Syndrome
}

\author{
Beuy Joob $^{1}$, Viroj Wiwanitkit ${ }^{2}$ \\ ${ }^{1}$ Sanitation 1 Medical Academic Center, Bangkok Thailand \\ ${ }^{2}$ Visiitng professor, Hainan Medical University, China \\ beuyjoob@hotmail.com
}

\begin{abstract}
Dear Editor, use of screening test for the cardiovascular patients is very interesting. The recent report by McCune et al. on diabetes screening for the patients with acute coronary syndrome (ACS) is very interesting [1]. McCune et al. reported result from audit and service improvement project and concluded that "introduction of $\mathrm{HbA}_{1 \mathrm{c}}$ as part of an ACS admission profile offers a simplified and accessible screening test for the early diagnosis and management of patients with diabetes [1]." Basically, it is no doubt that HbAlc can be more useful in detection on the patients with risk for diabetes mellitus. However, this big concern is on the cost. As McCune et al. mentioned the cost of $\mathrm{HbA1C}$ is more expensive than fasting blood glucose test [1]. In the present report, McCune et al. mentioned for the usefulness of universal screening based on the possibility that more risk case can be identified [1]. However, McCune et al. do not mentioned for cost effectiveness. Since McCune et al. do not report the result from screening according to NICE criteria and do compare the results from both alternative options, it is no possible to further assess for cost effectiveness. At present, according to the previous report, we can confirm that $\mathrm{HbA1c}$ test is more cost effective than fasting blood test [2]. But we cannot say anything about the screening using NICE criteria comparing to universal testing. Another interesting observation is the loss of follow-up screening test. In the service improvement project, not all cases received screening, which is not different from the observation in pre- service improvement project that the case meeting NICE criteria also get no follow-up screening. It seems that the big problem should be the follow-up of the patients to get the test, either by NICE guidelines or universal screening.
\end{abstract}

\section{Conflict of interest: No}

\section{REFERENCES}

[1] McCune C, Maynard S, McClements B, Lindsay JR. HbA1c for Diabetes Screening in Acute Coronary Syndrome: time for a reappraisal of the guidelines? Ulster Med J. 2015 Oct; 84(3):1546.

[2] Gillett M, Brennan A, Watson P, Khunti K, Davies M, Mostafa S, Gray LJ. The costeffectiveness of testing strategies for type 2 diabetes: a modelling study. Health Technol Assess. 2015 May; 19(33):1-80. 